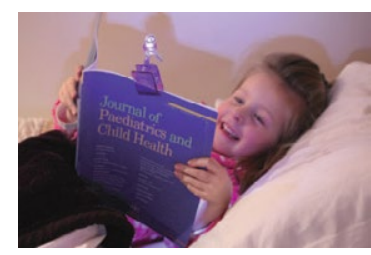

Edited by Katrina Williams (katrina.williams@rch.org.au)

Written by: Aaron Wiggins (Aaron.Wiggins@rch.org.au) and David Coghill

\title{
Can depression be prevented in children and adolescents?
}

Hetrick SE, Cox GR, Witt KG, Bir JJ, Merry SN. Cognitive behavioural therapy (CBT), thirdwave CBT and interpersonal therapy (IPT) based interventions for preventing depression in children and adolescents. Cochrane Database of Systematic Reviews 2016, Issue 8. Art. No.: CD003380. DOI: 10.1002/14651858.CD003380.pub4.

http://cochranelibrary-wiley.com/doi/10.1002/14651858.CD003380.pub4/abstract

\section{What is the review about?}

Does providing an evidence-based psychological intervention, Cognitive Behavioural Therapy (CBT), Interpersonal Therapy (IPT) or 'third wave CBT', reduce the risk of depression in children and adolescents? Primary and secondary outcomes were assessed at postintervention, short-term follow-up ( $\leq 3$ months), medium-term follow-up (4-12 months), and long-term follow-up (12-36 months). See Textbox 1 for primary and secondary outcomes and an explanation of terms used in this commentary.

\section{What are the findings?}

Primary outcomes

- A small reduction in self-rated depressive symptoms post-intervention (standardised mean difference (SMD) $-0.21,95 \% \mathrm{Cl}-0.27$ to -0.15 )

- Lowered risk of a depression diagnosis at 4 to 12 month follow-up, number needed to treat (NNT) = $33(95 \%$ Confidence Interval 22 to 148) with positive effect strongest in the 'indicated targeted' group and no positive effect when only studies $(n=13)$ that included an active control group (e.g. alternative curriculum or regular time off classes) were analysed

This is the author manuscript accepted for publication and has undergone full peer review but has not been through the copyediting, typesetting, pagination and proofreading process, which may lead to differences between this version and the Version of Record. Please cite this article as doi: $10.1111 /$ jpc.14267

This article is protected by copyright. All rights reserved. 
- No positive effects for primary outcomes in intervention groups at long-term followup

Secondary outcomes

- A small positive effect for clinician-rated depressive symptoms and general and social functioning post-intervention, with greater effect for targeted, compared to universal, programmes.

- No benefit for anxiety symptoms at any follow up, regardless of intervention group.

\section{What are the findings based on?}

Of the 83 randomised controlled trials (RCTs) or cluster-RCTs eligible for inclusion, 76 had adequate data to be included in the analysis. Sample sizes ranged from 18 to 5634 . Studies included children and adolescents from 16 different countries, mainly North America $(n=40)$ and Australia $(n=18)$. The mean age of young people was 14.2 years $(n=74$; range 8.8 to 19.7). Overall $40 \%$ were males $(n=79)$. For those studies that reported age and gender, there was a trend to a lower proportion of male participants in studies with older mean age. There were 52 studies of targeted interventions (one study had 3 trial arms) and 31 of universal interventions (one study had 2 trial arms). Participants in targeted studies were on average slightly older, 14.7 years (range 10.1 - 19.7) v 13.3 years (range 8.8 to 17.9 ), and had slightly fewer males, $36.5 \%$ v $45.1 \%$, than those in universal studies. The majority of trials ( $n=67)$ were conducted in a school setting. Seventy trials ( 73 trial arms; $n=13,829)$ provided data for the first primary outcome of self-reported depressive symptoms postintervention, and 32 trials $(n=5,965)$ data for depression at up to 12 month follow-up.

There was unclear or high risk of bias in many studies (Figure 1). Over half of included studies were judged to be at high risk of performance and detection bias due to inadequate blinding of subjects. 'Other biases' included lack of independence of investigators from the intervention provided. There was moderate heterogeneity for both depression at mediumterm follow up $\left(\mathrm{I}^{2}=47.0 \%\right)$ and self-reported depressive symptoms post-intervention $\left(\mathrm{I}^{2}=\right.$ 
57.0\%). The quality of evidence supporting findings for the primary outcomes were graded as of moderate to low quality using the Grading of Recommendations Assessment, Development and Evaluation (GRADE) framework.

\section{Implications of practice}

- Evidence-based psychological interventions for preventing depression were associated with a small reduction in both depressive symptoms post-intervention and a diagnosis of depression at 12 month follow up but not beyond, although the quality of supporting evidence was moderate to low.

- Current evidence favours further study of targeted intervention programmes over universal depression prevention programmes.

\section{Clinical perspective}

This Cochrane review ${ }^{1}$ provides an updated look at the current literature around depression prevention programmes for children and adolescents. In order to achieve greater homogeneity, this current update included only evidence-based psychological interventions and excluded education interventions. ${ }^{2}$ However, there was still a high level of variability across these studies and the authors were correctly cautious about offering clinical recommendations based on these findings.

One important difference of programmes that have been developed to prevent depression is some are offered to a whole population and others designed for high risk groups. This review suggests that the targeted approach should be favoured. Both CBT and IPT interventions are currently recommended for the treatment of clinical depressive disorders in children and adolescents. ${ }^{3,4}$ Providing these interventions to young people with subthreshold depressive symptoms may be effective in reducing symptom burden postintervention and risk of depression in the following year. There was also a positive effect for 
general and social functioning, but not anxiety symptoms post-intervention. A recent metaanalysis has explored the effectiveness of resilience-based school interventions (including CBT) in improving the mental health of children and adolescents. ${ }^{5}$ The authors found a positive effect in reducing both depressive and anxiety symptoms at short-term follow up (up to 11 months), but not beyond. ${ }^{5}$ The meta-analysis included 12 of the studies used in the updated Cochrane review and one study not available at the time of the analysis, a cluster-RCT of a universal intervention programme of 1,341 adolescents (intervention group $\mathrm{n}=665$ ) which did not demonstrate a reduction in depressive symptoms, compared to controls, at one or two year follow up. ${ }^{6}$ While it might be postulated that non-CBT interventions might produce a more generalised positive effect, it was the CBT-based interventions in the meta-analysis that were most effective (5). ${ }^{5}$

Whilst there is some evidence to support a small effect of preventative interventions when compared to treatment as usual (TAU), waitlist and no treatment, there is no clear evidence to support an effect compared to an active control. Therefore, there is currently not enough evidence to support preventative interventions, particularly for universal programmes. It is however still possible that larger well designed studies will in the future provide more support for preventative interventions in targeted populations.

\section{References}

1. Hetrick SE, Cox GR, Witt KG, Bir JJ, Merry SN. Cognitive behavioural therapy (CBT), third-wave CBT and interpersonal therapy (IPT) based interventions for preventing depression in children and adolescents. Cochrane Database of Systematic Reviews 2016, Issue 8. Art. No.: CD003380. DOI: 10.1002/14651858.CD003380.pub4.

2. Merry SN, Hetrick SE, Cox GR, Brudevold-Iversen T, Bir JJ, McDowell H. Psychological and educational interventions for preventing depression in children and adolescents. Cochrane Database of Systematic Reviews 2011, Issue 12. Art. No.: CD003380. DOI: 10.1002/14651858.CD003380.pub3.

3. National Collaborating Centre for Mental Health. Depression in children and young people: identification and management in primary, community and secondary care.

This article is protected by copyright. All rights reserved. 
The British Psychological Society and the Royal College of Psychiatrists, 2005. Link: https://www.ncbi.nlm.nih.gov/pubmedhealth/PMH0015779/pdf/PubMedHealth P MH0015779.pdf (accessed 3/8/18).

4. Malhi GS, Bassett D, Boyce P, et al. Royal Australian and New Zealand College of Psychiatrists clinical practice guidelines for mood disorders. ANZ J. Psychiatry 2015; 49: 1087-206.

5. Dray J, Bowman J, Campbell E, et al. Systematic review of universal resiliencefocused interventions targeting child and adolescent mental health in the school setting. J. Am. Acad. Child Adolesc. Psychiatry 2017; 56: 813-24.

6. Tak YR, Lichtwarck-Aschoff A, Gillham JE, Van Zundert RM, Engels RC. Universal school-based depression prevention 'Op Volle Kracht': a longitudinal cluster randomized controlled trial. J. Abnorm. Child Psychol. 2016; 44: 949-61. 
Textbox 1 Terms included in this review and their explanations

\begin{tabular}{|l|l|}
\hline Term & Explanations \\
\hline 'Third wave CBT' & $\begin{array}{l}\text { Mindfulness } \\
\text { Acceptance and commitment therapy (ACT) } \\
\text { Dialectical behavioural therapy (DBT) Positive psychology } \\
\text { Behavioural therapy }\end{array}$ \\
\hline At risk of depression & $\begin{array}{l}\text { Those who may go on to develop depression based on elevated } \\
\text { depressive symptoms at baseline ('indicated') or other risk factors } \\
\text { (e.g. family history of depression, parental conflict or death of a } \\
\text { parent) 'selected' }\end{array}$ \\
\hline Programme types & $\begin{array}{l}\text { Targeted studies included participants who were at risk of } \\
\text { depression. } \\
\text { Universal studies recruited participants regardless of their level of } \\
\text { depressive symptoms }\end{array}$ \\
\hline Primary outcomes & $\begin{array}{l}\text { Self-rated depressive symptoms post-intervention. } \\
\text { Depression diagnosis at follow up between 4 and 12 months }\end{array}$ \\
\hline Secondary outcomes & $\begin{array}{l}\text { Self-rated depressive symptoms or depressive diagnosis at follow } \\
\text { up, less than 3 months or greater than 12 months after intervention }\end{array}$ \\
\hline
\end{tabular}

This article is protected by copyright. All rights reserved. 
Figure 1 'Risk of bias' graph: Review authors' judgements about each risk of bian item presented as percentages across all included studies.

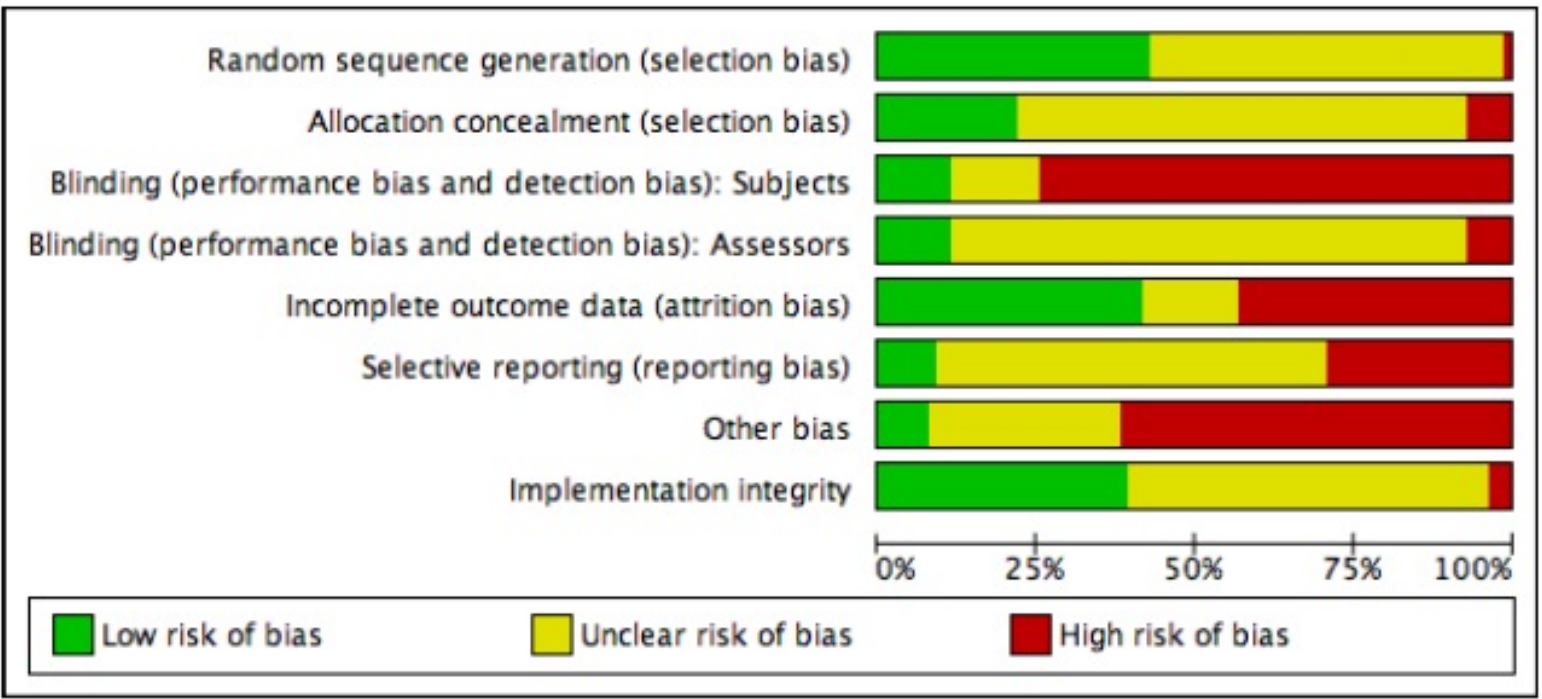

This article is protected by copyright. All rights reserved. 


\section{University Library}

\section{- M M I N E R VA A gateway to Melbourne's research publications}

Minerva Access is the Institutional Repository of The University of Melbourne

Author/s:

Wiggins, A;Coghill, D

Title:

Can depression be prevented in children and adolescents?

Date:

2018-12-01

Citation:

Wiggins, A. \& Coghill, D. (2018). Can depression be prevented in children and adolescents?. JOURNAL OF PAEDIATRICS AND CHILD HEALTH, 54 (12), pp.1386-1388. https://doi.org/10.1111/jpc. 14267.

Persistent Link:

http://hdl.handle.net/11343/284856 